Dicle University Journal of Engineering (DUJE)

web: http://dergipark.gov.tr/dumf

Araștırma Makalesi / Research Article

\title{
Hareketli Tabanlı Akarsularda Yan Savak Civarındaki Oyulma Derinliklerinin Genetik İfadeli Programlama İle Belirlenmesi
}

\author{
Determination Of Scour Depth Around Side Weir In Live Bed River With Genetic \\ Expression Programming \\ Hayrettin Kaya ${ }^{1}$, Fevzi Önen ${ }^{2 *}$ \\ ${ }^{1}$ Dicle Üniversitesi, Fen Bilimleri Enstitüsü, Diyarbakır, h-kaya@dsi.gov.tr, ORCID:0000-0002-9320-1236 \\ 2 Dicle Üniversitesi, İnşaat Mühendisliği Bölümü, Diyarbakır, fonen@ dicle.edu.tr, ORCID:0000-0002-2368-1035
}

\begin{tabular}{|c|c|}
\hline MAKALE BİLGILERİ & ÖZET \\
\hline Makale geçmişi: & $\begin{array}{l}\text { Yan savaklar su yüksekliğinin kontrol altında tutulması, sistemdeki atık suyun deşarj edilmesi ve debi } \\
\text { ölçümü gibi amaçlar için kullanılan ve de genel olarak akarsular üzerine inşa edilen hidrolik yapılardır. }\end{array}$ \\
\hline $\begin{array}{l}\text { Geliş: } 19 \text { Nisan } 2020 \\
\text { Düzeltme: } 15 \text { Mayis } 2020 \\
\text { Kabul: } 19 \text { Mayis } 2020\end{array}$ & $\begin{array}{l}\text { Hareketli tabanlı akarsularda en sik karşılaşılan hidrolik problemlerin başında oyulma problemi } \\
\text { gelmektedir. Hareketli tabanlı akarsularda yan savak civarındaki oyulma olayını araştıran çalışmalar }\end{array}$ \\
\hline $\begin{array}{l}\text { Hateketli Taban, Oyulma, Yan } \\
\text { savak, GEP }\end{array}$ & 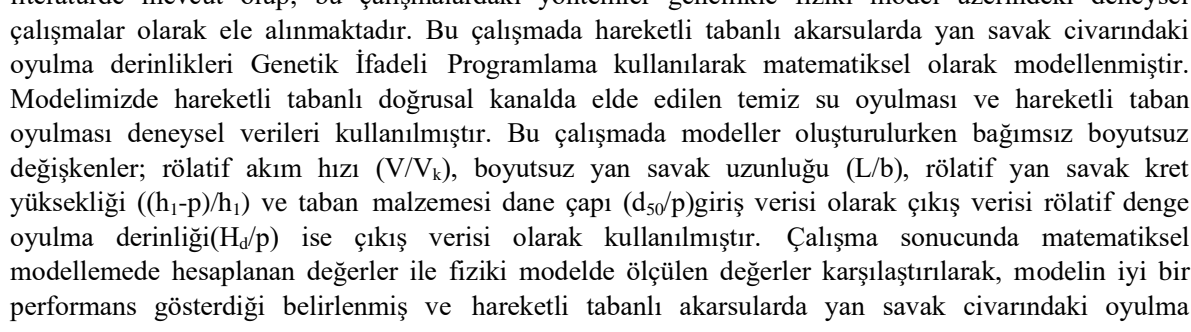 \\
\hline
\end{tabular}

Doi: $10.24012 /$ dumf. 723092

\begin{tabular}{|c|c|}
\hline ARTICLE INFO & ABSTRACT \\
\hline Article history: & Side weirs are hydraulic structures used for purposes such as controlling water height, discharging of \\
\hline $\begin{array}{l}\text { Received: } 19 \text { April } 2020 \\
\text { Revised: } 15 \text { May } 2020 \\
\text { Accepted: } 19 \text { May } 2020\end{array}$ & $\begin{array}{l}\text { waste water in the system and flow measurement and generally built on rivers. The most common } \\
\text { hydraulic problems in live-bed streams are the problem of scouring. Local scour may cause damage and } \\
\text { destruction of the bridge piers, side weirs or water dams. The data obtained in laboratory conditions or } \\
\text { in the model environment can be used to understand the hydraulic factors of the local scour. Studies }\end{array}$ \\
\hline Keywords: & investigating the scour around side weir on the live-bed river are available in the literature. However, \\
\hline Live bed, Scour, Side weir, GEP & $\begin{array}{l}\text { the methods in these studies are generally considered as experimental studies on the physical model. In } \\
\text { the literature, the number of studies researching the scour depth on the mathematical model is limited. In } \\
\text { this study, unattached non-dimensioned variables are formed while creating models; relative flow } \\
\text { velocity }\left(V / V_{c}\right) \text {, dimensionless side weir length }(L / b) \text {, relative side weir crest height }\left(\left(h_{1}-p\right) / h_{1}\right) \text { and bed } \\
\text { material grain diameter }\left(d_{50} / p\right) \text { using output data relative equilibrium scour depth }\left(H_{d} / p\right) \text {. As a result of } \\
\text { the study, the values calculated in the mathematical modeling and the values measured in the physical } \\
\text { model were determined to show a good performance and the scour depths around the side weir could be } \\
\text { determined by using Gene Expression Programming in the live-bed rivers. }\end{array}$ \\
\hline
\end{tabular}

* Sorumlu yazar / Correspondence

Fevzi Önen

$\bowtie$ fonen@dicle.edu.tr

Please cite this article in press as H. Kaya, F. Onen, "Hareketli Tabanlı Akarsularda Yan Savak Civarındaki Oyulma Derinliklerinin Genetik İfadeli Programlama İle Belirlenmesi", DUJE, vol. 11, no.3, pp. 1397-1406, September 2020. 


\section{Giriș}

Yan savaklar, bir kanaldaki fazla debinin azaltılması veya herhangi bir kanaldan ihtiyaç duyulan debinin alınması için kullanılan yapılardır. Sulama, hidroelektrik ve diğer hidrolik yapıların su temini amaçlı tesislerinin iletim kanalları, ihtiyaç ve ekonomi göz önüne alınarak optimum kapasiteye göre projelendirilir. Kanala giren fazla suyun taşarak çevreye zarar vermemesi için gerekli yerlere yan savaklar inşa edilmektedir. Yan savaklar kanalın sadece bir tarafina ya da her iki tarafina, çökeltim havuzları gibi yapıların yan tarafına yapıldıkları için yan savak olarak adlandırılır [1].

Mühendislik uygulamalarında yan savaklar sıkça başvurulan çözüm yollarından bir tanesidir. Yan savaklar genellikle sulama sistemlerinde, kanalizasyon şebekelerinde ve taşkın koruma yapılarında, barajlar ve hidroelektrik santrallerinde kullanılan yapılardır. Yan savaklar kullanılarak, sistemdeki atık suyun uzaklaştırılması ve su kayıplarının minimum seviyeye indirilmesi mümkün olmaktadır.

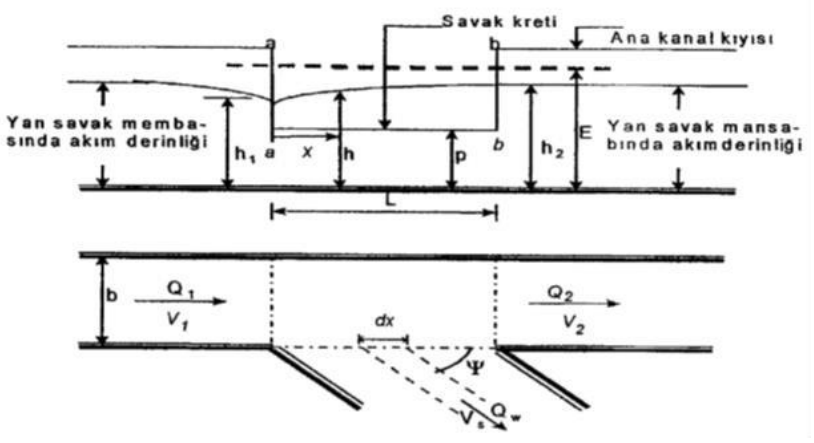

Şekil 1. Yan savak akımının planı ve kesiti [2]

Figure 1. Plan and section of the side weir flow

Şekil 1'de Yan savak akımının planı ve kesiti verilmiştir. $\mathrm{h}_{1}$, yan savak membasında ana kanal eksenindeki su derinliğini $(\mathrm{m}), \mathrm{h}_{2}$ yan savak mansabında ana kanal eksenindeki su derinliğini (m), h herhangi bir kesitteki su derinliğini (m), $\mathrm{Q}_{1}$ ana kanaldaki debiyi ( $\left.\mathrm{m}^{3} / \mathrm{s}\right), \mathrm{Q}_{2}$ yan savaktan sonraki ana kanal debisini $\left(\mathrm{m}^{3} / \mathrm{s}\right)$, $Q_{w}$ yansavaktan savaklanan debiyi $\left(\mathrm{m}^{3} / \mathrm{s}\right), \mathrm{V}_{1}$ yan savak membasında ortalama akım hızını $(\mathrm{m} / \mathrm{s})$, $\mathrm{V}_{2}$ yan savak mansabında ortalama akım hızını $(\mathrm{m} / \mathrm{s})$, Vs yan savaktan savaklanan akım hızını $(\mathrm{m} / \mathrm{s})$, b ana kanal genişliğini (m), L yan savak uzunluğunu (m), $\Psi$ savaklanma (sapma) açısını, p yan savak kret yüksekliğini (m), x yan savağın herhangi bir noktasının yan savak başlangıcına olan mesafesini göstermektedir.

Hareketli tabanlı kanallarda bulunan yan savaklarin kanal taban profiline ve ana kanaldaki akım özelliklerine önemli etkisi mevcuttur. Gerek yanal akım ve gerekse kanalda bulunan engel ve eğrilikler tarafindan yaratılan sekonder akım, ana kanaldaki taban profilinde ve hidrolik karakteristiklerinde çok önemli değişikliklere sebep olmaktadır.

Akım şiddeti yükseldiği zaman membadaki kayma gerilmesi taban malzemesinin karş1 koyacağı kritik kayma gerilme değerini aştığında membadan itibaren akım yönünde katı madde hareketi başlar. $\mathrm{Bu}$ hareket türbülans etkisiyle oluşan oyulma çukurundaki akımla birleşerek hareketli taban oyulmasını oluşturmaktadır.

Literatürde hareketli tabanlı akarsularda yan savaklarda meydana gelen oyulma derinliği ile ilgili çok sayıda araştırma bulunmamaktadır. Ülkemiz gibi akarsu sayısının bir hayli fazla olduğu bir coğrafyada hareketli taban üzerinde bulunan yan savakta meydana gelecek oyulma ile ilgili araştırmalar önem arz etmektedir.

Önen [1], çalışmasında hareketli tabanlı kanal boyunca dikdörtgen kesitli ve keskin kenarlı yan savaklar için nehir rejimli akım şartlarında ve serbest savaklanma durumunda fiziki model üzerinde seri deneyler gerçekleştirmiştir. Temiz su oyulması hali $\left(0,5<\mathrm{V}_{1} / \mathrm{V}_{\mathrm{kr}}<1\right)$ ve hareketli taban oyulması hali $\left(0,95-1,0<\mathrm{V}_{1} / \mathrm{V}_{\mathrm{kr}}<2,5\right)$ için rölatif denge oyulma derinliği incelenmiştir.

Emiroğlu ve ark. [3], $\theta=90^{\circ}$ 'lik kıvrımlı kanalda nehir rejimi şartlarında ve kohezyonsuz zeminde oyulma derinliği ile ilgili deneysel çalışmalar yapmışlardır. Çalışmada $\mathrm{V}_{1} / \mathrm{V}_{\mathrm{kr}}<1$ için temiz su oyulması durumunda kanal tabanında bulunan 
kohezyonsuz zeminde taban dalgalanmasinın oluşmadığını gözlemlemişler. Savaklanma miktarının artmayla sekonder akımın şiddetinin arttığını ve bununla beraber oyulma derinliği miktarının artarak yan savak çıkışında oluştuğunu gözlemlemişlerdir.

Onen ve Agaccioglu [4], Alüvyon tabanlı bir kanalda yan savak civarında temiz su oyulması derinliğini belirlemeye yönelik deneysel çalışmaları dikdörtgen kanalda yapmışlardır. Alüvyon tabanlı kanaldaki oyulma derinliğinin akış hızına, yan savak uzunluğuna, hidrolik su seviyesine ve katı madde dane çapına bağlı olduğu tespit edilmiştir. Temiz su oyulması derinliğinin zamanla arttığ 1 ve yaklaşma akış hızına bağlı olarak denge durumuna asimptotik olarak yaklaştığı tespit edilmiştir.

Dilek [5], kohezyonlu malzeme tabanlı doğrusal bir kanalda, dikdörtgen kesitli bir yan savak civarındaki oyulma derinliğini deneysel olarak incelemiştir. Çalışma süresince doğrusal bir kanala yerleştirilen, dikdörtgen kesitli yan savak civarındaki oyulma derinliklerinin tespiti için yaklaşık 30 deney yapılmıştır. Boyut analizi sonucunda, rölatif denge oyulma derinliği $\mathrm{H}_{\mathrm{de}} / \mathrm{h}_{1}{ }^{\prime}$ nin; $1 / \mathrm{F}_{\mathrm{r}}{ }^{2}, \mathrm{~L} / \mathrm{b}, \mathrm{C}$, Wc ve $\tau_{\mathrm{s}}$ 'e bağl olduğu bulunmuştur.

Önen [6], genetik algoritmalara (GA) ve genetik programlamaya dayalı bir algoritma olan Genetik İfadeli Programlama (GEP) yöntemini kullanarak kıvrımlı kanal boyunca yan savak civarındaki temiz su oyulmasını tahmin etmek için yeni bir formülasyon geliştirmiştir. Çalışmada, geliştirilen GEP modellerinin açık formülasyonları sunulmuş ve ayrıca çoklu doğrusal regresyon (MLR) ve çoklu doğrusal olmayan regresyon (MNRL) modelleri de kullanılarak denklemler de elde edilmiştir.

Varol [7], çalışmasında yan savak oyulmasını kohezyonlu zeminlerde deneysel olarak incelemiştir. Çalışmada kumlu-killi tabanlı bir dikdörtgen enkesitli kanal boyunca, nehir rejimi akım şartlarında ( $\mathrm{Fr}=0.33-0.81), \mathrm{L}=25,40$ ve 50 $\mathrm{cm}$ uzunluklu, taban malzemesinden itibaren $\mathrm{p}=7,12$ ve $17 \mathrm{~cm}$ kret yükseklikli dikdörtgen yan savak etrafinda ana kanal tabanında meydana gelen oyulma ve rölatif denge oyulma derinlikleri incelenmiştir.

Emiroğlu ve ark. [8], trapez biçimli labirent bir yan savakta kullanılacak olan antivorteks yapının debi kapasitesi ve temiz su oyulması üzerindeki etkisini araştırmışlardır. Çalışmada Froude Sayıs1 $\left(\mathrm{F}_{1}\right)$, boyutsuz kret yüksekliği (p/y), boyutsuz açık savak uzunluğu $(\mathrm{L} / \mathrm{b})$, boyutsuz efektif kret uzunluğu (L/Lef) ve yan duvar açısı $(\alpha)$ 'nın değişken değerleri kullanılmıştır. Çalışma boyunca çoklu ve sıralı deneyler yapılarak antivorteks yapının tipinin ve konumunun debi kapasitesi ve oyulma üzerindeki etkileri araştırılmış ve optimum değerler saptanmıştır.

Tunç ve ark. [9], dikdörtgen enkesitli alüvyon tabanlı bir kanalda kararlı akım şartları ve serbest savaklanma durumu için üçgen labirent yan savak civarındaki yerel oyulma derinliklerini deneysel olarak araştırmışlardır. Çalışmada Üçgen labirent yan savak etrafında oluşan maksimum oyulma derinliklerini belirlemek için farklı koşullarda bir dizi deney gerçekleştirilmiş; deneylerde savağın membasinda ve mansabinda farklı boyutlarda oyulma derinlikleri gözlemlenmiş ve maksimum oyulma derinliğinin, çoğunlukla üçgen labirent yan savağın mansap ucunda oluştuğu gözlenmiştir.

$\mathrm{Bu}$ çalışmada hareketli tabanlı kanallarda yan savak civarında oluşan oyulma derinlikleri Genetik İfadeli Programlama model ile incelenecektir. Ayrıca fiziki modelde ölçülen oyulma derinlikleri ile model sonuçları karşılaştırılıp oluşturulan matematiksel modellerin doğruluğu ortaya konulacaktır.

\section{Materyal ve metot}

$\mathrm{Bu}$ çalışmada hareketli tabanlı akarsularda yan savak civarındaki oyulma derinlikleri Genetik İfadeli Programlama kullanılarak matematiksel olarak modellenmiştir. Matematiksel modelleme gerçek ya da fiziki olan bir durumun ya da sürecin matematik diline aktarılma ve matematiksel olarak ifade edilmesidir. Önen [1] tarafından yapılan doktora tez çalışmasındaki 
deneysel veriler kullanılarak modellemeler yapılmıştır.

\section{Deney kanalı ve deneysel çalışma}

Önen [1] tarafından yapılan deneysel çalışmalar Y.T.Ü İnşaat Fakültesi İnşaat Mühendisliği Bölümü Hidrolik Anabilim Dalı Hidrolik Laboratuvarında mevcut dikdörtgen en kesitli 180 derecelik kivrıml kanalda gerçekleştirilmiştir. Mevcut kanal toplam 0,90 $\mathrm{m}$ genişliğinde ve $0,60 \mathrm{~m}$ yüksekliğinde alüminyum tabanlıdır. Deney kanalının planı ve boyuna kesiti Şekil 2'de verilmiştir.
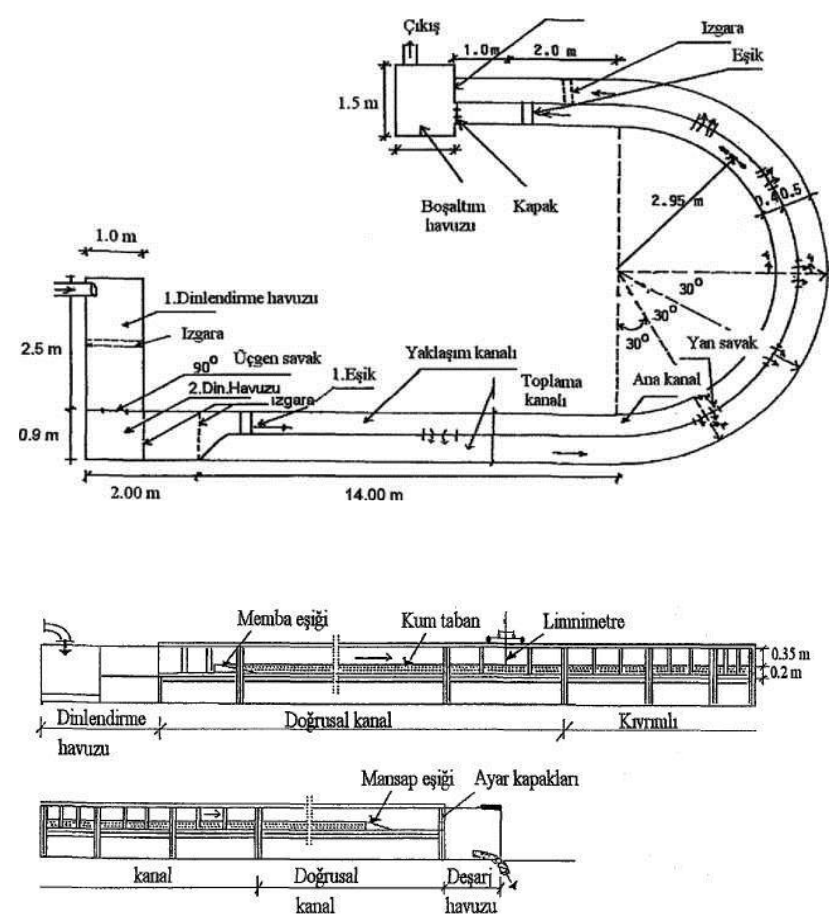

Şekil 2. Deney kanalının planı ve boyuna kesiti [1]

Figure 2. Plan and longitudinal section of the test channel

Mevcut kanal, ana kanal genişliği net $0,4 \mathrm{~m}$ ve toplama (sağanak) kanalı genişliği $0,5 \mathrm{~m}$ olacak şekilde birbirine paralel iki kanaldan oluşmaktadır.

Deney kanalı birbirine seri olarak bağlanmış yedi bölümden oluşmaktadır. Bunlar sırasıyla; Yaklaşım Kanalı, Kıvrımlı Kanal, Doğrusal
Çıkış Kanalı, Yan Savak Ayırma Duvarı, Toplama (Sağanak) Kanalı, Boşaltım Havuzu, Hareketli Seviye Ölçüm Arabasıdır. Çalışma, 14 m'lik doğrusal yaklaşım kanalı, $180^{\circ}$ 'lik 2.95 m eksen eğrilik yarıçapına sahip $90 \mathrm{~cm}$ genişliğinde kıvrımlı kanal ve kıvrımdan sonra 3 m'lik doğrusal mansap kanalında gerçekleştirilmiştir. Deneyler, doğrusal kanalda $\mathrm{L}=25,40$ ve $50 \mathrm{~cm}$ uzunluklu ve kum tabandan itibaren $\mathrm{p}=7,12$ ve $17 \mathrm{~cm}$ kret yükseklikli yan savaklar için yapılmıştır. Ana kanalın memba ve mansap uçlarına $20 \mathrm{~cm}$ yüksekliğinde iki eşik yerleştirilmiş ve aralarına $20 \mathrm{~cm}$ yüksekliğinde, $\mathrm{d}_{50}=1,15 \mathrm{~mm}$ ve $\sigma \mathrm{g}=1,74$ olan kuvars kumu serilmiştir. Kanalda akım hızları kanalın sonunda bulunan radyal kapaklarla ayarlanmıştır. Limnimetre yardımıyla yan savak bölgesinde oluşan maksimum oyulma derinliği ölçülmüştür. Çalışmada denge oyulma süresi ile denge oyulma derinliği arasındaki ilişki ortaya konmuştur. $\mathrm{Bu}$ ilişkide deney süresinin denge oyulma süresinin \%50'si olması halinde oyulma derinliğinin denge oyulma derinliğinin \%9095 'ini geçtiği görülmüştür. Doğrusal kanalda temiz su oyulması ve hareketli taban oyulması için toplam 250'ye yakın deney yapılmıştır [1].

\section{Genetik ifadeli programlama}

Bilgisayar programlamada, genetik ifadeli programlama (GEP), bilgisayar programlarını veya matematiksel modelleri oluşturan evrimsel bir algoritmadir. $\mathrm{Bu}$ bilgisayar programları, yaşayan bir organizmaya benzeyen boyutlarını, şekillerini ve kompozisyonlarını değiştirerek öğrenen ve adapte olan karmaşık ağaçsal yapılardır. Ve canlı organizmalar gibi, GEP bilgisayar programları da sabit uzunlukta basit doğrusal kromozomlarda kodlanır. Dolayısıyla GEP, genetik bilgiyi tutmak ve iletmek için basit bir genomdan ve çevreyi keşfetmek ve ona uyum sağlamak için karmaşık bir fenotipten faydalanan bir genotip-fenotip sistemidir.

Genetik ifadeli programlama, lineer kromozomlar ve analiz ağaçlarını fenotip olarak işler, genotip-fenotip sistemi oluşturur. $\mathrm{Bu}$ 
genotip-fenotip sistemi her bir kromozomdaki çoklu ayrıştırma ağaçlarını kodlar. $\mathrm{Bu}$ durum GEP tarafindan oluşturulan bilgisayar programlarının çoklu ayrıştırma ağaçlarından oluştuğu anlamına gelir. Bu ayrıştırma ağaçları gen ifadesinin bir sonucu olduğundan, GEP'te bunlara ifade ağacı denir.

Genetik İfadeli Programlamanın temel aşamaları, Şekil 3'te şematik olarak gösterilmiştir. İşlem, belirli sayıda kişinin kromozomlarının rastgele üretilmesiyle başlar. Daha sonra bu kromozomlar analiz edilir ve her bir bireyin uygunluğu, bir dizi uygunluk vakasına karşı değerlendirilir. Bireyler daha sonra o ortamdaki performanslarına göre seçilir. $\mathrm{Bu}$ yeni bireyler sırayla aynı gelişim sürecine tabi tutulur. İşlem, belirli sayıda nesiller için veya iyi bir çözüm bulunana kadar tekrar edilir.

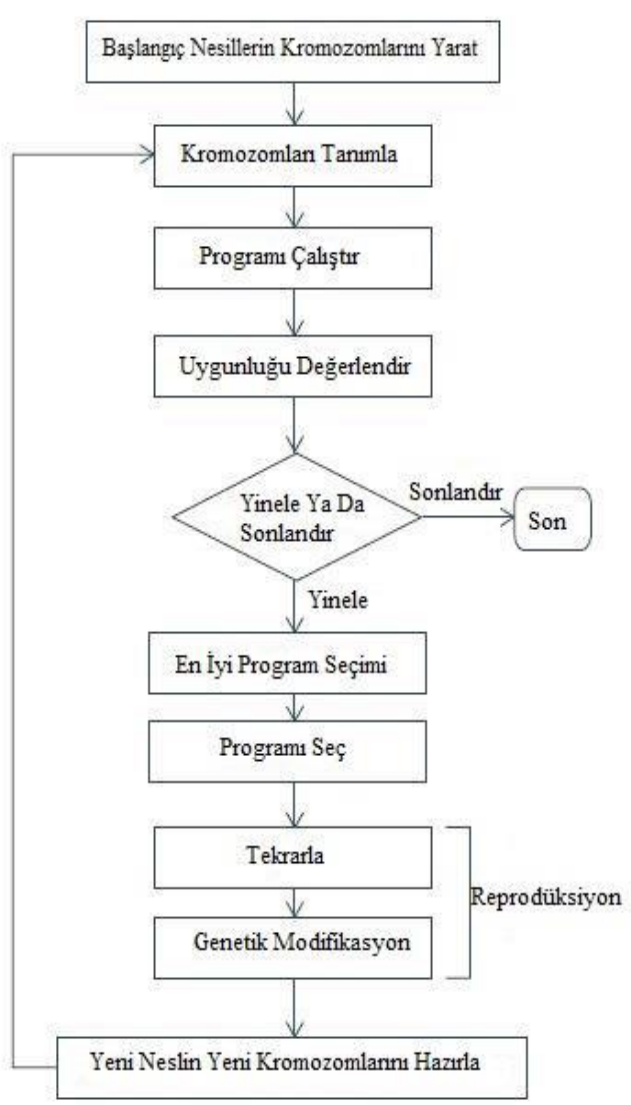

Şekil 3. Genetik ifadeli algoritmanın akış şeması [10]
Figure 3. Flow chart of genetic expression algorithm

\section{Bulgular ve Tartışma}

$\mathrm{Bu}$ çalışmada amaç; hareketli tabanlı bir akarsuda yan savak civarındaki oyulma derinliklerini etkileyen parametreleri belirlemek ve bu parametreler arasında var olan ilişkileri belirlemektir. Önen [1] tarafından yapılan fiziki model, GEP yöntemiyle matematiksel ortama aktarılmıştır. Genetik İfadeli Programlama (GEP) yöntemiyle farklı modeller oluşturarak, bu parametrelerin oyulma derinliği miktarına etkisini ve daha önce oluşturulmuş olan fiziki modelle olan bağlantıları ortaya çıkarılmıştır.

Genetik İfadeli Programlama yöntemiyle hesaplanan değerlerin doğruluğu için regresyon analizi kullanılacaktır. Regresyon analizi, değişkenler arasındaki ilişkilerin araştırılması için kullanılan istatistiksel bir modeldir [11]. Genetik İfadeli Programlama yaklaşımı ile hesaplanan rölatif denge oyulma derinliği $\left(\mathrm{H}_{\mathrm{d}} / \mathrm{p}\right)$, fiziki modelde laboratuvar ortamında ölçülen değerlerle karşılaştırılmış ve modellerin performansı için de belirleme Determinasyon Katsayısı $\left(\mathrm{R}^{2}\right)$ ve Ortalama Karesel Hata Kökü (RMSE) kullanılmıştır.

Regresyon modelinde hesaplanacak $\mathrm{R}^{2}$ değeri her zaman 0 ve 1 arasında çıkar. Bağımlı değişkenler arasında mantıklı bir ilişki öne sürebilmek için yüksek bir $\mathrm{R}^{2}$ değeri ve düşük RMSE değeri gereklidir. Bu durum bir modelin güvenirliliği ve tahmin amaçlı kullanılabilmesi için oldukça önemlidir [11].

\section{Genetik ifadeli programlama modelinin oluşturulması}

Genetik İfadeli Programlama uygulamasında, tüm uygunluk durumları için belirli bir hata payı içerisinde doğru sonuçları regresyon analizi ile veren bir formül oluşturulmalıdır. $\mathrm{Bu}$ formül için çok küçük mutlak aralıklar seçilirse akış oldukça yavaşlar ve sonuca ulaşmak zorlaşır. Öte yandan büyük aralıklar seçilirse 
gerçeklikten uzak sonuçlarla karşı karşıya kalmak mümkündür [12].

$\mathrm{Bu}$ sorunu çözmek için akışı bozmadan sorunu çözmeyi sağlayan evrimsel strateji geliştirilmiştir. $\mathrm{Bu}$ sistem akışı bozmadan mümkün olan en küçük hata sınırları içinde çözümü bulmayı hedefler. Matematiksel olarak $f_{\mathrm{i}}$ formülü seçilen hata mutlak bir denklemle ifade edilir [11]:

$$
f_{i}=\sum_{j=1}^{c_{i}}\left(M-\left|C_{(i, j)}-T_{j}\right|\right)
$$

$\mathrm{Bu}$ çalışmada model oluşturulurken hata olarak mutlak hata kullanılacak, yani (1) fonksiyonu kullanılacaktır.

Ferreira [10], çalışmasında ise GEP Modelinin kullanımında ve hazırlanmasında beş önemli basamak olduğunu belirtmiştir. İlk basamak; GEP'e girilecek olan uygun formülün oluşturulmasıdır. Modelin oluşturulmasında ilk aşamada kullanılan fonksiyon;

$$
H_{d} / p=\sum_{j=1}^{c_{i}}\left(M-\left|C_{(i, j)}-T_{j}\right|\right)
$$

Burada, $\mathrm{H}_{\mathrm{d}} / \mathrm{p}$ : Rölatif denge oyulma derinliği; M: Seçim aralığı C(i,j): Bireysel kromozomlar tarafından değiştirilen değer (i: uygun durumlar için, $\mathrm{j}$ : uygun olmayan durumlar için), Tj: En uygun durum için hedef değer. Eğer $\mid \mathrm{C}(\mathrm{i}, \mathrm{j})$ - Tj| (doğruluk) 0.01 ' den az ya da eşit ise, o zaman doğruluk sıfira eşit olur ve fi=fmax=CiM. Bu durumda, $M=100$ alınır ve bu sebeple fmax $=1,000$ olur.

İkinci önemli basamak, kromozomları üretmek için $\mathrm{T}$ dizinimi ve $\mathrm{f}$ fonksiyonu seçilir. $\mathrm{Bu}$ problemde dizinimler bağımsız değişkenlerden $\mathrm{H}_{\mathrm{d}} / \mathrm{p}=\mathrm{f}\left(\mathrm{V} / \mathrm{V}_{\mathrm{kr}}, \mathrm{L} / \mathrm{b},\left(\mathrm{h}_{1}-\mathrm{p}\right) / \mathrm{h}_{1}, \mathrm{~d}_{50} / \mathrm{p}\right)$ oluşmaktadır. Uygun fonksiyon kümesinin seçiminde gerekli tüm fonksiyonları içerecek iyi bir tahmin yapılır. $\mathrm{Bu}$ durumda, dört temel matematiksel işlem $(+,-, *, /)$ ve bazı temel matematiksel fonksiyonlar $\left(1 / x, \quad x^{1 / 2}, \quad x^{1 / 3}, \quad x^{1 / 4}, \quad x^{2}, \quad x^{3}\right)$ kullanılmıştır.
Üçüncü basamakta; kromozomal yapı, yani baş kısmın uzunluğu ve gen sayısı belirlenmektedir. $\mathrm{Bu}$ kısımda, eğitim dizinimindeki ortalama karesel hata (RMSE) en uygun fonksiyon olarak alınmıştır. Dördüncü önemli basamak ise; bağlantı fonksiyonun seçimidir (toplama, çıkarma, çarpma, bölme). $\mathrm{Bu}$ durumda, çoğaltma yöntemiyle ifade ağaçlarından bağlantı kurulur. Son olarak, beşinci önemli basamakta; genetik katılımcıların, varyasyon ve oranlarından kaynaklı seçilimler yapılır. Tüm genetik kullanıcıların kombinasyonu (mutasyon, aktarma ve yeniden birleştirme) en uygun GEP Modelinin Parametreleri ile kullanılmıştır [12].

$\mathrm{Bu}$ çalışmada en iyi GEP modelini belirlemek için yapılan denemelerden sonra baş uzunluğu, $\mathrm{h}=8$ ve kromozom başına 3 gen seçilmiştir. Bağlantı fonksiyonu olarak da çarpma kullanılmıștır. Son olarak tüm genetik operatörlerin birleşimi genetik operatörler kümesi olarak kullanılmıştır. GEP modelinin eğitim parametreleri Tablo 1'de verilmiştir.

Tablo 1. Modellemede Kullanılan Değişkenler

\begin{tabular}{|c|c|c|}
\hline P1 & Fonksiyon Seti & $+,-x / 2 \sqrt{x}, \exp , x^{2}, x^{3}, \sqrt[3]{x}, 1 / x$ \\
\hline $\mathrm{P} 2$ & Gen Say151 & 3 \\
\hline P3 & Başlık Sayısı & 8 \\
\hline P4 & Bağlantı Fonksiyonu & Çarpma \\
\hline P5 & Jenerasyon Sayisı & Jenerasyon Sayis1 Deǧişik \\
\hline P6 & Kromozomlar & $30-45$ \\
\hline P7 & Mutasyon Oranı & 0.044 \\
\hline P8 & Ters Çevirme Oranı & 0.1 \\
\hline P9 & Tek Nokta Yeni Kombinasyon Oranı & 0.3 \\
\hline P10 & İki Nokta Yeni Kombinasyon Oranı & 0.1 \\
\hline P11 & Gen Yeniden Kombinasyon Oranı & 0.1 \\
\hline P12 & Gen Yer Değiştirme Oranı & 0.1 \\
\hline
\end{tabular}

Table 1. Variables Used in Modeling

\section{GEP Yöntemi İle Oluşturulan Modeller}

GEP yöntemi ile model oluşturma çalışmalarında; fiziki modelden ölçüm yoluyla elde edilen bağımsız dört değişken $\left(\mathrm{V} / \mathrm{V}_{\mathrm{kr}}, \mathrm{L} / \mathrm{b}\right.$, 
$\left.\left(h_{1}-b\right) / h_{1}, d_{50} / p\right)$ ve ç1ktı verisi $H_{d} /$ p'ye ait 235 farklı veri bulunmaktadır. $\mathrm{Bu} 235$ adet verinin \%80'i yani 188 veri Eğitim (training) seti olarak kullanılmış olup geriye kalan \%20'lik 47 adet veri Doğrulama (test/validation) verisi olarak kullanılmıştır. Test verileri programın yaptığg 1 hesaplamaların karşılaştırılması için kullanılacaktır. Çalışmada kullanılan bağımsız değişkenlere ait deney aralıkları ve yan savağa ait boyut aralıkları Çizelge 2'de verilmiştir.

Tablo 2. Çalışmada kullanılan yan savak boyutları ve bağımsız değişkenlere ait deney aralıkları [13]

Table 2. Side weir dimensions and experimental ranges used in the study

\begin{tabular}{|c|c|c|c|c|c|c|c|c|}
\hline $\begin{array}{c}\mathrm{p} \\
(\mathrm{cm})\end{array}$ & $\begin{array}{c}\mathrm{L} \\
(\mathrm{cm})\end{array}$ & $\begin{array}{c}\mathrm{h}_{1} \\
(\mathrm{~cm})\end{array}$ & $\left(\mathrm{h}_{1}-\mathrm{p}\right) \mathrm{h}_{1}$ & $\mathrm{~d} 50 / \mathrm{p}$ & $\mathrm{L} / \mathrm{b}$ & $\begin{array}{c}\mathrm{V}_{1} \\
(\mathrm{~m} / \mathrm{s})\end{array}$ & $\begin{array}{c}\mathrm{V}_{\mathrm{s}} \\
(\mathrm{m} / \mathrm{s})\end{array}$ & $\mathrm{V}_{1} \mathrm{~V}_{\mathrm{c}}$ \\
\hline$(1)$ & $(2)$ & $(3)$ & $(4)$ & $(6)$ & $(7)$ & $(8)$ & $(9)$ & $(10)$ \\
\hline 7 & 25 & $12-20$ & $0.45-0.66$ & 0.0164 & 0.625 & $0.20-0.91$ & $0.43-0.47$ & $0.46-2.08$ \\
\hline 12 & 25 & $19-27$ & $0.37-0.55$ & 0.0096 & 0.625 & $0.22-0.84$ & $0.46-0.49$ & $0.47-1.85$ \\
\hline 17 & 25 & $27-33$ & $0.38-0.49$ & 0.0068 & 0.625 & $0.3-0.63$ & $0.49-0.5$ & $0.60-1.31$ \\
\hline 7 & 40 & $14-20$ & $0.50-0.63$ & 0.0164 & 1.0 & $0.22-0.99$ & $0.44-0.47$ & $0.50-2.25$ \\
\hline 12 & 40 & $19-27$ & $0.38-0.56$ & 0.0096 & 1.0 & $0.23-0.98$ & $0.46-0.49$ & $0.50-2.16$ \\
\hline 17 & 40 & $24-29$ & $0.30-0.40$ & 0.0068 & 1.0 & $0.26-0.79$ & $0.48-0.50$ & $0.55-1.67$ \\
\hline 7 & 50 & $12-18$ & $0.44-0.60$ & 0.0164 & 1.25 & $0.21-1.00$ & $0.43-0.46$ & $0.49-2.32$ \\
\hline 12 & 50 & $17-24$ & $0.30-0.50$ & 0.0096 & 1.25 & $0.21-0.95$ & $0.46-0.48$ & $0.50-2.13$ \\
\hline 17 & 50 & $24-28$ & $0.30-0.40$ & 0.0068 & 1.25 & $0.27-0.81$ & $0.48-0.49$ & $0.58-1.72$ \\
\hline
\end{tabular}

Model çalışmalarında 4 değişkenli, 3 değişkenli ve 2 değişkenli varyasyonlar oluşturularak sonuçlar gözlenmiştir. İlk oluşturulan model olan Model-1'de tüm değişkenler $\mathrm{V} / \mathrm{V}_{\mathrm{kr}}, \mathrm{L} / \mathrm{b}$, $\left(\mathrm{h}_{1}-\mathrm{p}\right) / \mathrm{h}_{1}, \mathrm{~d}_{50} / \mathrm{p}$ hesaplamalara ilave edilmiştir. Model-2'de V/Vkr, $\left(\mathrm{h}_{1}-\mathrm{p}\right) / \mathrm{h}_{1}, \mathrm{~d}_{50} / \mathrm{p}$, Model-3'te $\mathrm{L} / \mathrm{b}, \quad\left(\mathrm{h}_{1}-\mathrm{p}\right) / \mathrm{h}_{1}, \mathrm{~d}_{50} / \mathrm{p}$, Model-4'te $\mathrm{V} / \mathrm{V}_{\mathrm{kr}}, \mathrm{L} / \mathrm{b}$, $\mathrm{d}_{50} / \mathrm{p}, \quad$ Model-5'te $\mathrm{V} / \mathrm{V}_{\mathrm{kr}}, \quad \mathrm{L} / \mathrm{b}, \quad\left(\mathrm{h}_{1}-\mathrm{p}\right) / \mathrm{h}_{1}$ değişkenleri olmak üzere 3 değişkenli hesaplama yapılmıştır. Model-6'da V/ $\mathrm{V}_{\mathrm{kr}}$, ( $\mathrm{h}_{1-}$ p)/h , Model-7'de (h-p)/h 1 , d50/p ve Model-8'de $\mathrm{L} / \mathrm{b}, \quad\left(\mathrm{h}_{1}-\mathrm{p}\right) / \mathrm{h}_{1}$ olmak üzere 2 değişkenli hesaplamalar yapılmıştır. Toplam oluşturulan model sayısı 8 olmak üzere Model-1 için ifade ağac1 (ET)'nin şekilsel gösterimi, GEP formülleri, fiziki modelde elde edilen değerler ve matematiksel model değerlerin karşılaştırılmasını gösteren grafikler verilmiştir. Diğer modeller Model-2, 3, 4, 5, 6, 7, 8 için ise Eğitim (eğitim) ve Doğrulama (test/validation) hesaplamalarına ait $\mathrm{R}^{2}$ ve RMSE değerleri tablo şeklinde verilmiştir.

\section{Model-1}

Genetik İfadeli Programlama yöntemi ile Model-1 için ifade ağacı (ET) elde edilmiştir. $\mathrm{Bu}$ ifade ağacından yola çıkılarak GEP formülü elde edilmiştir. Elde edilen GEP formülü şu șekildedir.

$\mathrm{y}=(((\mathrm{d}[2]+\mathrm{d}[1])+\mathrm{d}[0])+\mathrm{d}[2]) *((\mathrm{~d}[2]+\mathrm{d}[1]) *(\mathrm{~d}[2$ ] $\mathrm{d}[3]))) *(((\mathrm{~d}[0] * \mathrm{~d}[0]) *(\mathrm{G} 2 \mathrm{C} 7 * \mathrm{~d}[3])) * \operatorname{pow}((\mathrm{d}[2$ ]$\left.\left.\left.\left.^{*} \mathrm{~d}[1]\right), 3\right)\right)+\mathrm{d}[2]\right) ; *((\operatorname{sqrt}((\mathrm{d}[3] * \mathrm{G} 3 \mathrm{C} 3))+\operatorname{pow}(\mathrm{d}[$ $2], 3))-((\mathrm{d}[3] * \mathrm{~d}[3])-(\mathrm{d}[1] * \mathrm{~d}[3])))$;

formülde bulunan sabitlerin değeri $\mathrm{G} 2 \mathrm{C} 7=$ 15.06 ve $\mathrm{G} 3 \mathrm{C} 3=10.63$ 'dir. Çıktı verimiz $\mathrm{y}=\mathrm{H}_{\mathrm{d}} / \mathrm{p}$ olmak üzere $\mathrm{d}[0]=\mathrm{V} / \mathrm{V}_{\mathrm{kr}}, \mathrm{d}[1]=\mathrm{L} / \mathrm{b}, \mathrm{d}[2]=\left(\mathrm{h}_{1}\right.$ $\mathrm{p}) / \mathrm{h}_{1}$ ve $\mathrm{d}[3]=\mathrm{d}_{50} / \mathrm{p}$ 'dir. Burada $\mathrm{V} / \mathrm{V}_{\mathrm{kr}}$ : Yan savağı memba ve mansabında bulunan ana kanaldaki ortalama hızın, tane hareketi yani oyulma başlama anındaki kritik hıza oranı(Rölatif akım hızı), L/b: Boyutsuz yan savak uzunluğu, $\left(h_{1}-p\right) / h_{1}$ : rölatif yan savak kret yüksekliği, $\mathrm{d}_{50} / \mathrm{p}$ : Taban malzemesi dane çap1, çıkış verisi olarak elde edilen $\mathrm{H}_{\mathrm{d}} / \mathrm{p}$ ise rölatif denge oyulma derinliğini verir. İlgili sabitler, değişkenler ve çıtı verisi formülde yerine birakıld1ktan sonra:

$$
\begin{aligned}
& \mathrm{Hd} / \mathrm{p}=\left(\left(\mathrm{V} / \mathrm{V}_{\mathrm{kr}}+\mathrm{L} / \mathrm{b}+2\left(\mathrm{~h}_{1}-\mathrm{p}\right) / \mathrm{h}_{1}\right) *\left(\mathrm{~L} / \mathrm{b}+\left(\mathrm{h}_{1}-\mathrm{p}\right) / \mathrm{h}_{1}\right)\right. \\
&\left.*\left(\left(\mathrm{~h}_{1}-\mathrm{p}\right) / \mathrm{h}_{1}-\mathrm{d}_{50} / \mathrm{p}\right)\right) \\
& *\left(\left(\mathrm{~V} / \mathrm{V}_{\mathrm{kr}}\right)^{2} *\left(\mathrm{~d}_{50} / \mathrm{p} *-15.06\right)\right. \\
&\left.\left.*\left(\left(\left(\mathrm{~h}_{1}-\mathrm{p}\right) / \mathrm{h}_{1} * \mathrm{~L} / \mathrm{b}\right)^{3}\right)+\left(\mathrm{h}_{1}-\mathrm{p}\right) / \mathrm{h}_{1}\right)\right) \\
& *\left(\left(\sqrt{\mathrm{d}_{50} / \mathrm{p} * 10.63}+\left(\left(\mathrm{h}_{1}-\mathrm{p}\right) / \mathrm{h}_{1}\right)^{3}\right)\right. \\
&\left.-\left(\left(\mathrm{d}_{50} / \mathrm{p}\right)^{3}-\left(\mathrm{L} / \mathrm{b} *\left(\mathrm{~d}_{50} / \mathrm{p}\right)\right)\right)\right)
\end{aligned}
$$


şeklinde elde edilir.

Model-1'de yapılan hesaplamalar sonucunda Eğitim (training) verilerine ait $\mathrm{R}^{2}=0.864$ ve $\mathrm{RMSE}=0.145 \quad$ olarak, Doğrulama (test/validation) verilerine ait $\mathrm{R}^{2}=0.858$ ve $\mathrm{RMSE}=0.153$ olarak bulunmuştur.

Eğitim verileri için önerilen GEP formülleri referans alınarak ortaya çıkan model verileri ile fiziki modelde ölçülen değerlerin karşılaştırılması Şekil 4 ve Şekil 5'te verilmiştir.
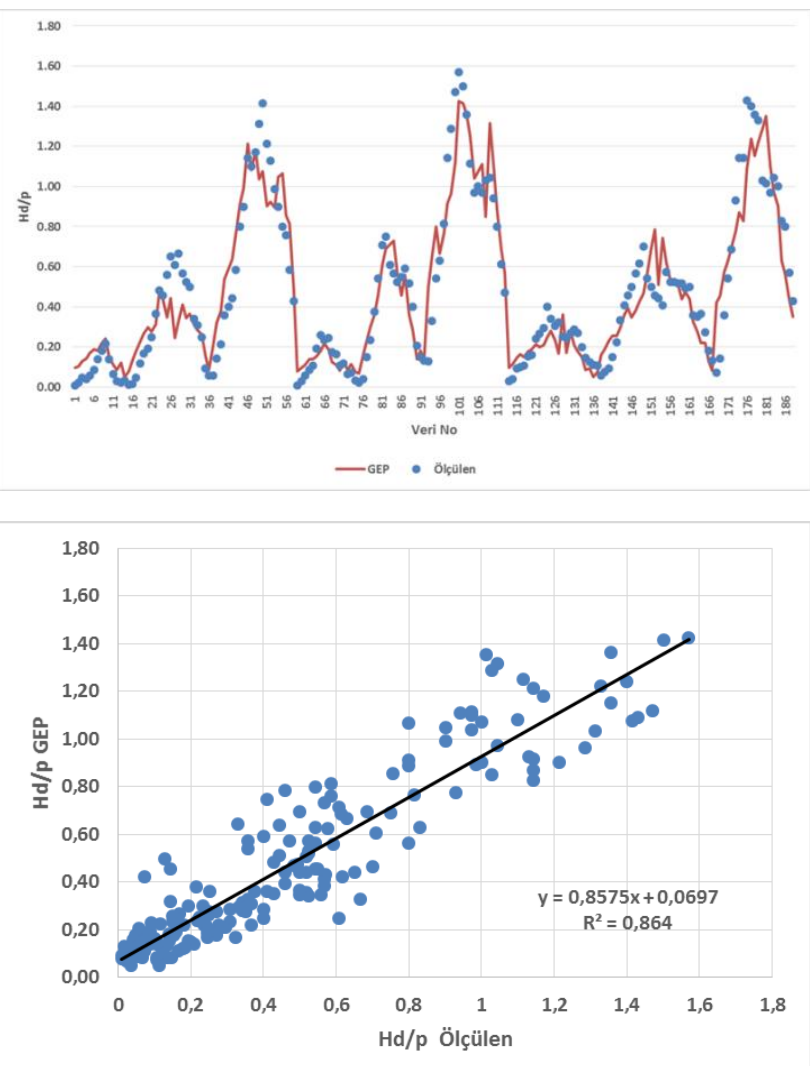

Şekil 4. Model-1'in eğitim verilerinde GEP model değerleri ile fiziki modelde ölçülen değerlerin karşılaştırılması

Figure 4. Comparison of GEP model values and values measured in the physical model in the training data of Model-1

Test verileri için önerilen GEP formülleri referans alınarak ortaya çıkan model verileri ile fiziki modelde ölçülen değerlerle karşılaştırılması Şekil 4 ve Şekil 5'de verilmiştir.
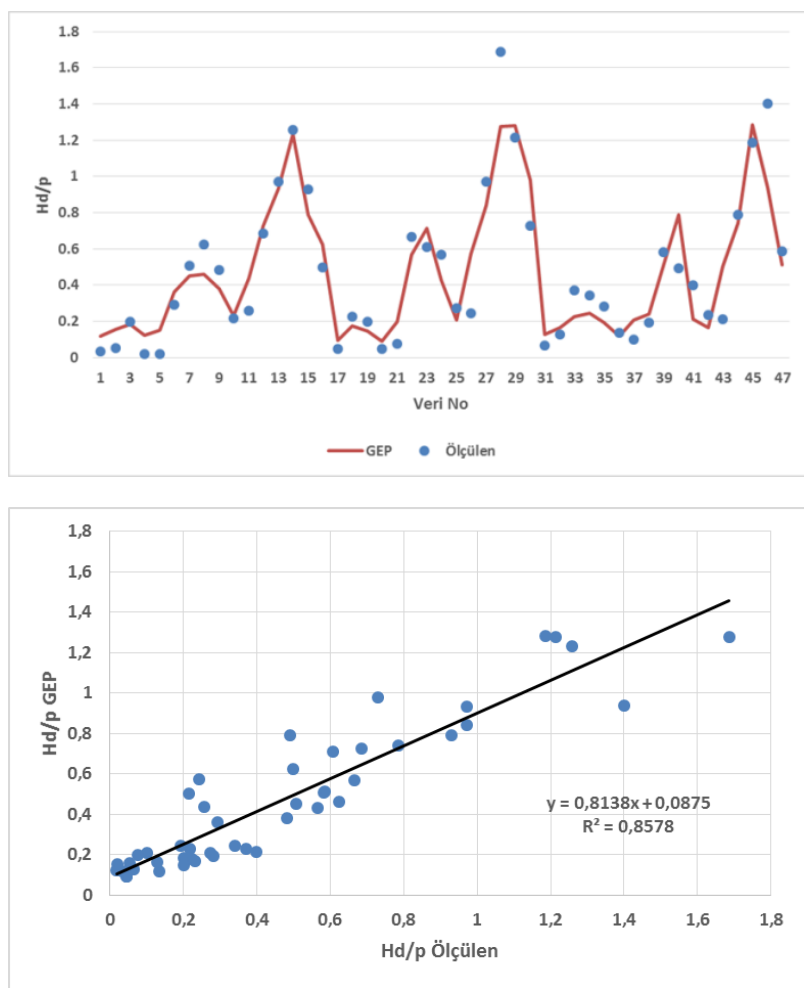

Şekil 5. Model-1'in test verilerinde GEP model değerleri ile fiziki modelde ölçülen değerlerin karşılaştırılması

Figure 5. Comparison of GEP model values and values measured in the physical model in the test data of Model-1

Model-1'e ait yukarıdaki grafikler, $\mathrm{R}^{2}$ ve $\mathrm{RMSE}$ değerleri incelendiğinde modelin güvenilir olduğu ve iyi bir performans gösterdiği açıkça görülmektedir.

Şekil 4'de görüldüğü gibi GEP modeline ait değerler ile fiziki modelde ölçülen gerçek değerlerin grafiklerinin benzerlik gösterdiği görülmüş ve grafikler arasında ciddi bir sapma görülmemiştir. Şekil 5'de test verilerine ait grafiklerin eğitim veri grafikleri ile benzerlik 
gösterdiği görülmektedir. Bu durum da modelin düzgün çalıştığını göstermektedir.

Regresyon analizi yönteminde kullanılan determinasyon katsayısı yani $\mathrm{R}^{2}$; 0 ile 1 arasında bir sonuç vermektedir. $\mathrm{R}^{2}$ 'nin 0.8 'den büyük çıkması modelin güvenilir bir model olduğunu gösterirken, $\mathrm{R}^{2}$ 1'e yaklaştıkça modelin doğruluğu artar. RMSE değeri ise Ortalama Karesel Hataların Kökü olarak ifade edilebilir. RMSE değeri GEP modelinde elde edilen değerlerle fiziki modelde ölçülen değerlerin ortalama farkını ortaya koyar. RMSE değerinin düşük çıkması modelin doğruluğu hakkında fikir verir. Model-1'de yapilan hesaplamalar sonucunda eğitim verilerine ait $\mathrm{R}^{2}=0.864$ ve $\mathrm{RMSE}=0.145$ olarak, test verilerine ait
$\mathrm{R}^{2}=0.858$ ve $\mathrm{RMSE}=0.153$ olarak bulunmuștur. Burada eğitim verilerine ait $\mathrm{R}^{2}$ değerinin yüksek RMSE değerinin ise düşük çıkması modelin doğru çalıştığını gösterir. Test verilerine ait $\mathrm{R}^{2}$ ve RMSE değerlerindeki kısmi farklılık model oluşturulurken kullanılan veri sayısından kaynaklanmakta olup test ve eğitim verilerinin yakın çıkması modelin iyi bir performans gösterdiğini ortaya koymaktadır.

Model-1'den sonra oluşturulan modellere ait ifade ağacı, GEP formülleri ve benzeşim grafikleri bu çalışma içinde yer almamakta olup tüm modellere ait eğitim ve test verilerine ait $\mathrm{R}^{2}$ ve RMSE değerleri aşağıdaki tabloda verilmiştir [15].

Tablo 3. GEP yöntemi ile oluşturulan modellere ait $R^{2}$ ve RMSE değerleri

Table 3. $R^{2}$ and RMSE values of models created by GEP method

\begin{tabular}{|c|c|c|c|c|c|c|}
\hline \multirow{2}{*}{ Model No } & \multirow{2}{*}{ Değişken Tipi } & \multicolumn{2}{|c|}{ Training Veriler } & \multicolumn{2}{|c|}{ Test Verileri } & \multirow{2}{*}{\begin{tabular}{|c} 
Değişk en \\
Sayıs ı
\end{tabular}} \\
\hline & & $\mathbf{R}^{2}$ & RMSE & $\mathbf{R}^{2}$ & RMSE & \\
\hline Model-1 & $\mathrm{Hd} / \mathrm{p}=\mathrm{f}(\mathrm{V} / \mathrm{Vkr}, \mathrm{L} / \mathrm{b},(\mathrm{h} 1-\mathrm{p}) / \mathrm{h} 1, \mathrm{~d} 50 / \mathrm{p})$ & 0.864 & 0.145 & 0.858 & 0.153 & 4 \\
\hline Model-2 & $\mathrm{Hd} / \mathrm{p}=\mathrm{f}(\mathrm{V} / \mathrm{Vkr},(\mathrm{hl}-\mathrm{p}) / \mathrm{h} 1, \mathrm{~d} 50 / \mathrm{p})$ & 0.903 & 0.123 & 0.892 & 0.133 & \multirow{4}{*}{3} \\
\hline Model-3 & $\mathrm{Hd} / \mathrm{p}=\mathrm{f}(\mathrm{V} / \mathrm{Vkr}, \mathrm{L} / \mathrm{b},(\mathrm{hl}-\mathrm{p}) / \mathrm{hl})$ & 0.890 & 0.130 & 0.883 & 0.138 & \\
\hline Model-4 & $\mathrm{Hd} / \mathrm{p}=\mathrm{f}(\mathrm{L} / \mathrm{b},(\mathrm{hl}-\mathrm{p}) / \mathrm{hl}, \mathrm{d} 50 / \mathrm{p})$ & 0.845 & 0.155 & 0.830 & 0.167 & \\
\hline Model-5 & $\mathrm{Hd} / \mathrm{p}=\mathrm{f}(\mathrm{V} / \mathrm{Vkr}, \mathrm{L} / \mathrm{b}, \mathrm{d} 50 / \mathrm{p})$ & 0.727 & 0.209 & 0.673 & 0.234 & \\
\hline Model-6 & $\mathrm{Hd} / \mathrm{p}=\mathrm{f}(\mathrm{V} / \mathrm{Vkr},(\mathrm{hl}-\mathrm{p}) / \mathrm{hl})$ & 0.852 & 0.152 & 0.819 & 0.172 & \multirow{3}{*}{2} \\
\hline Model-7 & $\mathrm{Hd} / \mathrm{p}=\mathrm{f}(\mathrm{L} / \mathrm{b},(\mathrm{h} 1-\mathrm{p}) / \mathrm{h} 1)$ & 0.847 & 0.154 & 0.833 & 0.165 & \\
\hline Model-8 & $\mathrm{Hd} / \mathrm{p}=\mathrm{f}((\mathrm{h} 1-\mathrm{p}) / \mathrm{h} 1, \mathrm{~d} 50 / \mathrm{p})$ & 0.765 & 0.191 & 0.740 & 0.205 & \\
\hline
\end{tabular}




\section{Sonuç ve Öneriler}

$\mathrm{Bu}$ çalışmanın amacı hidrolik yapıların tasarımında ve işletme aşamasında karşılaşılan ana problemlerden olan taban oyulmasinin hareketli taban ve yan savak özelinde araştırılması, matematiksel olarak modellenmesi ve Genetik İfadeli Programlama yöntemi ile hesaplanan modellerin kullanılabilirliği, doğruluğu ve performansının ortaya konmasıdır.

$\mathrm{Bu}$ çalışmasında modeller oluşturulurken bağımsız boyutsuz değişkenler rölatif akım hızı $\left(\mathrm{V} / \mathrm{V}_{\mathrm{kr}}\right)$, yan savak uzunluğu $(\mathrm{L} / \mathrm{b})$, rölatif yan savak kret yüksekliği $\left(\left(\mathrm{h}_{1}-\mathrm{p}\right) / \mathrm{h}_{1}\right)$ ve taban malzemesi dane çapı $\left(\mathrm{d}_{50} / \mathrm{p}\right)$ kullanılarak rölatif denge oyulma derinliği $\left(\mathrm{H}_{\mathrm{d}} / \mathrm{p}\right)$ elde edilmiştir.

Çalışma sonucunda matematiksel modellemede hesaplanan değerler ile fiziki modelde ölçülen değerler karşılaştırılarak modelin iyi bir performans gösterdiği belirlenmiş ve hareketli tabanlı akarsularda yan savak civarındaki oyulma derinliklerinin GEP kullanılarak belirlenebileceği ortaya konulmuştur.

Elde edilen $\mathrm{R}^{2}$ ve RMSE değerleri incelendiğinde genel olarak 3 ve 4 değişkenli modellerin iyi performans gösterdiği, 2 değişkenli modellerin ise daha düşük performans gösterdiği görülmüştür. 4 değişkenli Model- 1 de $\mathrm{R}^{2}=0.864$ ve $\mathrm{RMSE}=0.145$ ve 3 değişkenli Model-2 de ise $\mathrm{R}^{2}=0.903$ ve $\mathrm{RMSE}=0.123$ değerleri elde edilmiştir.

Model sonuçlarından $\left(\mathrm{h}_{1}-\mathrm{p}\right) / \mathrm{h}_{1}$ ve $\mathrm{V} / \mathrm{V}_{\mathrm{kr}}$ ' in rölatif denge oyulma derinliğinin belirlenmesinde oldukça etkili olduğu $\mathrm{d}_{50} / \mathrm{p}$ ve $\mathrm{L} / \mathrm{b}$ değişkenlerinin ise daha az etkili olduğu tespit edilmiştir.

\section{Teşekkür}

$\mathrm{Bu}$ çalışma, Dicle Üniversitesi Bilimsel Araştırma Projeleri (DÜBAP) Mühendislik 18.010 numaralı proje kapsamında desteklenmiştir.

\section{Kaynaklar}

[1] Önen, F., (2005), Hareketli tabanlı akarsularda yanal akımın hidrodinamiğinin incelenmesi. Doktora Tezi, YTÜ Fen Bilimleri Enstitüsü, İstanbul. 175.
[2] [2] Agaccioglu, H., Onen, F., (2005), Clear-water scour at a side-weir intersection along the bend. Irrigation and Drainage, 54.5 553-569.

[3] Emiroğlu, M. E., Kaya, N.,Öztürk, M. (2007), Investigation of labyrinth side weir flow and scouring at the lateral intake region in a curved channel. Engineering Science Research Grant Group, TÜBİTAK Proje No: 104M394.

[4] Onen, F., Agaccioglu, H., (2007), Scour at a sideweir intersection located on an alluvial river. Hydrology Research, 38(2): 165-176.

[5] Dilek, Y., (2011), Kohezyonlu malzeme tabanl akarsulara yerleștirilen yan savak etrafindaki oyulma derinliğinin deneysel incelenmesi. Yüksek Lisans Tezi, YTÜ Fen Bilimleri Enstitüsü, İstanbul. 87.

[6] Onen, F., (2014), GEP prediction of scour around a side weir in curved channel, Journal of Environmental Engineering and Landscape Management, 22(3): 161-170.

[7] Varol, F.A., (2015), Yan savak akımlarının etkisindeki kohezyonlu taban malzemesinin oyulma probleminin deneysel incelenmesi. Yüksek Lisans Tezi, YTÜ Fen Bilimleri Enstitüsü, İstanbul. 233

[8] Emiroğlu, M.E., Göğüs, M., Tunç, M., İslamoğlu, K., (2016), Effects of Antivortex Structures Installed on Trapezoidal Labyrinth Side Weirs on Discharge Capacity and Scouring. Journal of Irrigation and Drainage Engineering, 143(6), 04017006

[9] Tunç, M., Emiroğlu, M. E., (2017), Investigation of live-bed scour at labyrinth side weirs. Firat University Turkish Journal of Science \& Technology, 13(1): 129-136.

[10] Ferreira, C., (2006), Automatically Defined Functions in Gene Expression Programming. Studies in Computational Intelligence, 13: 21-56

[11] Sykes, A.O., (1993), An Introduction to Regression Analysis. Coase-Sandor Working Paper Series in Law and Economics.

[12] Ferreira, C., (2001), Gene Expression Programming: A New Adaptive Algorithm for Solving Problems. Complex Systems, 13(2): 87-129

[13] Onen, F., (2014), Prediction of scour at a side-weir with GEP, ANN and regression models. Arabian Journal for Science and Engineering, 39(8), 60316041.

[14] Onen, F., Agaccioglu, H., (2013), Live bed scour at a side-weir intersection located on an alluvial channel. Irrigation and Drainage, 62(4), 488-500.

[15] Kaya, H., (2019), Hareketli tabanlı akarsularda yan savak civarındaki oyulma derinliklerinin genetik ifadeli programlama ile belirlenmesi. Yüksek Lisans Tezi, D.Ü Fen Bilimleri Enstitüsü, Diyarbakır. 79. 